\title{
The effect of changing attitudes to Down's syndrome in the management of complete atrioventricular septal defects
}

\author{
Kerstin Åmark, Jan Sunnegårdh
}

\begin{abstract}
Objectives-To describe the evaluation, decision making, and care of children with a complete atrioventricular septal defect (CAVSD).

Study design-Retrospective study of 136 consecutive cases from 1970 to 1996.

Results-A total of 115 (85\%) children had Down's syndrome. Denial of surgery without obvious medical reasons was more common in the early years, as was parental refusal of offered surgery and institutional care of the children. Improved results in later years encouraged surgical treatment for all these patients, but more liberal attitudes towards patients with Down's syndrome preceded the improved results. The use of echocardiography as a screening method for all newborns with Down's syndrome made it possible to plan for correction within the 1st months of life.

Conclusions-Changing attitudes in society and widespread use of echocardiography have significantly improved the management of children with a CAVSD and Down's syndrome.

(Arch Dis Child 1999;81:151-154)
\end{abstract}

Keywords: persistent common atrioventricular canal; Down's syndrome; public opinion; diagnostic techniques; sex; congenital heart disease

Department

(Cardiology)

Sahlgrenska University

Hospital, S-416 85

Göteborg, Sweden

$\mathrm{K}$ Åmark

J Sunnegårdh

Correspondence to:

Dr Åmark.

Accepted 19 March 1999

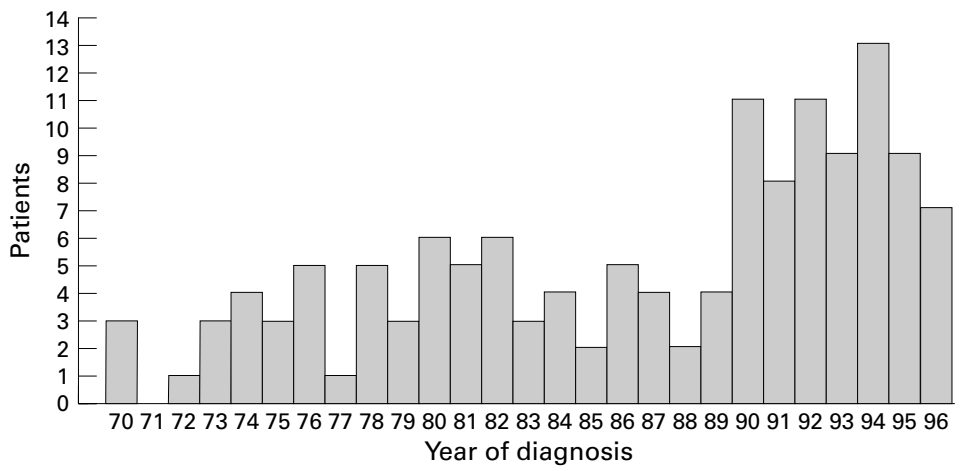

Figure 1 Numbers of children with complete atrioventricular septal defect from 1970 to 1996. two dimensional echocardiography and Doppler ultrasound. ${ }^{3}{ }^{4}$ Reports on preoperative evaluation of CAVSD are few, as are reports on protocols for cardiac evaluation of children with Down's syndrome. Our study describes diagnostic measures and management of children with CAVSD in our institution since 1970.

\section{Materials and methods}

All patients with CAVSD in our institution between 1970 and 1996 were studied retrospectively. Relevant data were collected from patient files. Cases with unbalanced CAVSD (that is, severe underdevelopment of one of the chambers) and patients with ventricular outflow obstructions or obstructions of the great arteries were excluded. Two dimensional echocardiography has been available in our unit since 1983 (March), and colour Doppler has been available since 1990 (August).

Statistical analyses included calculations of 95\% confidence intervals (CI) between two independent proportions. When three proportions were compared, a Z-value of 2.40 was used instead of 1.96. Where appropriate, Fisher's exact test was used, and significance was expressed in terms of a $\mathrm{p}$ value. Age at diagnosis over time was studied by means of a linear regression model. Log (age) was set as the dependent variable, and time was set as the independent variable. Calculated diagnostic median ages were determined at the end points of the curve in 1970 and 1996. The ratios of the median ages at end points were calculated to see the difference in age at diagnosis between patients with and without Down's syndrome. Standard deviation scores on weight and length were determined using a Swedish standard reference. ${ }^{5}$

\section{Results}

There were 136 patients with CAVSD, and surgery was eventually performed on 106 $(78 \%)$. Figure 1 shows the number of children diagnosed each year and table 1 gives the median age, length, and weight at diagnosis.

Of the 136 children, 115 (85\%) had Down's syndrome, and one had trisomy of chromosome 18. The numbers of girls and boys were

Table 1 Median age, length, and weight at diagnosis of 136 children with CAVSD

\begin{tabular}{lll}
\hline & Median (range) & SD median (range) \\
\hline Age (days) & $30(1$ to 4165$)$ & $-3(-8$ to 1.5$)$ \\
Length $(\mathrm{cm})$ & $61(40$ to 126$)$ & $-3(-8$ to 2.5$)$ \\
Weight $(\mathrm{kg})$ & $5.5(1.6$ to 24.2$)$ & \\
\hline
\end{tabular}


Table 2 Sex of children with complete atrioventricular septal defect

\begin{tabular}{lll}
\hline & Girls & Boys \\
\hline Down's syndrome & $59 / 115$ & $56 / 115$ \\
Non-Down's syndrome & $17 / 21$ & $4 / 21$ \\
\hline
\end{tabular}

95\% CI for differences in sex proportions between Down's and non-Down's syndrome groups (0.105 to 0.488$)$.

Table 3 Associated congenital heart defects in patients with CAVSD

\begin{tabular}{ll}
\hline Heart defect & Number (\%) \\
\hline PDA & $43(32)$ \\
ASD secundum & $31(23)$ \\
Persistent left caval vein & $4(3)$ \\
Apical VSD & $4(3)^{\star}$ \\
Aberrant right subclavian artery & $2(1)$ \\
Single coronary artery (left) & $1(0.7)$ \\
\hline
\end{tabular}

More than one congenital heart defect was found in 17 patients. ^Two patients without Down's syndrome. Comparison between Down's syndrome and non-Down's syndrome patients regarding presence of additional VSD: Fisher's exact test, $p=0.11$. ASD, atrial septal defect; PDA, persistent ductus arteriosus; VSD, ventricular septal defect.

similar in patients with Down's syndrome, but there were significantly more girls in the group without Down's syndrome (table 2).

Congenital heart defects in addition to CAVSD were present in 69 patients $(51 \%)$. The most frequent defect was persistent ductus arteriosus in 43 cases $(32 \%)$. Seventeen $(12.5 \%)$ had more than one associated defect, and the most common combination of intercurrent cardiac anomalies was persistent ductus arteriosus and atrial septal defect (ASD) secundum, which occurred in 12 patients $(9 \%)$. There was no significant difference in the presence of additional ventricular septal defects (VSDs) in patients with or without Down's syndrome (table 3).

Extracardiac malformations were found in 14 cases $(10 \%)$. This condition was present in about the same frequency in patients with (11 of 115) and without Down's syndrome (three of 21). Four patients had duodenal atresia, two had pes equinovarus et adductus, two had hydronephrosis, and one had rectal prolapse (all patients with Down's syndrome). Three patients had oesophageal atresia (two of whom had Down's syndrome). One child had microcephaly, and one had a malformation of the sacrum, both of whom did not have Down's syndrome.

Median age at confirmation of diagnosis decreased in the whole group from 210 days between 1970 and 1980 to 10 days between 1991 and 1996. Analysis of calculated median ages at diagnosis showed that children with Down's syndrome were diagnosed significantly later in 1970 than were children without

Table 4 Diagnostic errors and mode of investigation

\begin{tabular}{llll}
\hline Diagnostic method & Error & Proportion & $95 \%$ CI for 3 proportions \\
\hline Invasive & $3 / 28^{\star}$ & $\mathrm{p} 1$ & -0.099 to 0.271 (p1:p2) \\
Echocardiography & $12 / 62 \dagger$ & $\mathrm{p} 2$ & -0.060 to 0.261 (p2:p3) \\
Invasive and echocardiography & $4 / 43 \ddagger$ & $\mathrm{p} 3$ & -0.162 to 0.190 (p1:p3)
\end{tabular}

${ }^{\star}$ One persistent ductus arteriosus (PDA) that had to be reoperated and two persistent left caval veins.

†One apical ventricular septal defect (VSD) and one PDA that were reoperated. One misinterpreted for a partial atrioventricular septal defect. Four PDA and five atrial septal defect (ASD) secundum.

‡One PDA, one ASD secundum, and two persistent left caval veins.

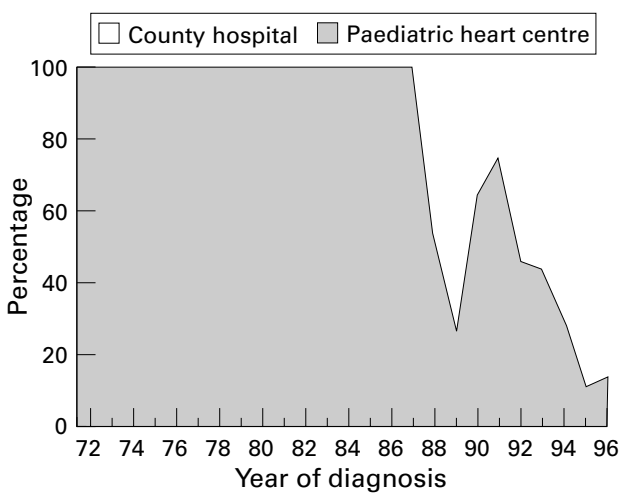

Figure 2 Place of diagnosis in 136 children with complete atrioventricular septal defect from 1970 to 1996.

Down's syndrome. In 1970, the calculated median age at diagnosis was 861 days in the Down's syndrome patient group, whereas it was 56 days in children without Down's syndrome ( $95 \%$ CI for the ratio of median ages, 3.13 to 76.10$)$. In 1996, children with Down's syndrome were diagnosed earlier than were children without Down's syndrome, and the calculated median ages were 4 days and 33 days, respectively $(95 \%$ CI for the ratio of median ages was reversed, 0.059 to 0.29 ).

Invasive studies were performed in 71 patients $(52 \%)$, including left ventricular angiography in 68 and right ventricular angiography in 47 . The median value of $\mathrm{Qp} / \mathrm{Qs}$ (the relation between pulmonary blood flow to systemic blood flow) in invasively studied patients was 2.3 (range, 0.6-8). A steady decline in the use of invasive preoperative study was seen after 1986. Two dimensional echocardiography was increasingly used as the only preoperative diagnostic method after 1988. The diagnosis was confirmed in our institution in all patients until 1988. In 1996, only $14 \%$ of the patients were diagnosed at our University Hospital because most were diagnosed in county hospitals (fig 2). All patients were finally evaluated in our institution before surgery.

Diagnostic errors occurred in 19 patients. These were persistent arterial ducts in seven patients, ASD secundum in six, persistent left caval veins in four, an apical VSD in one, and one patient in whom a complete defect was taken for a partial atrioventricular septal defect (AVSD). The errors were found at surgery in 13 patients, at postoperative echocardiography in two, at postoperative catheterisation in one, and at postmortem examination in three. The frequency of erroneous diagnosis did not differ significantly between the two diagnostic methods (table 4).

Twenty eight children (21\%) had no surgical treatment. No child was denied surgery after 1980, except for one baby in 1990 with trisomy

Table 5 Reasons for not performing surgery

\begin{tabular}{ll}
\hline Reason & Number (\%) \\
\hline Considered impossible to correct & $17(61)^{\star}$ \\
Death before offered surgery was performed & $6(21)$ \\
Parental refusal & $4(14)$ \\
Moved away & $1(4)$
\end{tabular}

Surgery was not performed in 28 patients.

^Including one patient in 1990 with trisomy 18. 
Table 6 Differences in decision making before and after 1980 in children with CAVSD and Down's syndrome

\begin{tabular}{llll}
\hline & $1970-80$ & $1981-96$ & p Value \\
\hline $\begin{array}{llll}\text { Denial of surgery in spite of acceptable PVR }{ }^{\star} \text { or without shunt } \\
\quad \text { evaluation }\end{array}$ & $4 / 28^{\star}$ & $0 / 87$ & $<0.05$ \\
Acceptance of early correction without shunt evaluation & $0 / 28$ & $58 / 87$ & $<0.001$ \\
Parental refusal of offered surgery & $4 / 28$ & $1 / 87$ & $<0.05$ \\
\hline p Values, Fisher's exact test. & & \\
${ }^{\star}$ Qp/Qs was not evaluated in two patients; surgery was not considered an alternative & \\
in spite of young age at diagnosis (3 months and 6 months, respectively). & \\
PVR, pulmonary vascular resistance (Qp/Qs $>2: 1){ }^{6}$
\end{tabular}

Table 7 Caregivers of children with CAVSD and Down's syndrome before and after 1980

\begin{tabular}{llll}
\hline Caregiver & $1970-80$ & $1981-96$ & p Value $^{*}$ \\
\hline Institution & $6 / 28$ & $0 / 87$ & $<0.001$ \\
Foster parents & $0 / 28$ & $2 / 87$ & $\mathrm{NS}$ \\
Biological mother & $22 / 28$ & $85 / 87$ & $<0.05$ \\
\hline `Fisher's exact test. & & &
\end{tabular}

${ }^{\star}$ Fisher's exact test.

of chromosome 18. Table 5 summarises the reasons for denial of surgery. Presence of Down's syndrome influenced management during the early years of our study period. A significant proportion of children with Down's syndrome were not offered surgery before 1981 , in spite of a relatively low pulmonary vascular resistance (Qp:Qs > 2.0), ${ }^{6}$ or without shunt evaluation being performed. Parental refusal of offered surgery was also more common before 1981 than after (table 6). A significantly higher proportion of children with CAVSD and Down's syndrome were also living apart from their biological mothers, and institutional care from birth was more common during the same time period (table 7).

\section{Discussion}

One limitation of retrospective studies on clinical decision making covering a long time period is that not all the information based on the different diagnostic methods is available for every patient. Our patient population is skewed in such a way that more patients with CAVSD were evaluated in the latter period, which can be explained by the centralisation of paediatric cardiac surgery in Sweden to two centres, including ours. Other factors explaining the increased number of patients in recent years may be a higher awareness of children with congenital heart defects in general, better organisation of paediatric cardiology services, and improved surgical results. Different attitudes towards the treatment and care of children with Down's syndrome also may have caused an uneven referral of children with CAVSD and Down's syndrome during our study period.

Our main finding was the change in diagnostic modes for children with CAVSD: the use of invasive study ceased, and ultrasound became the sole method for confirmation of diagnosis. This means that, in the latter period, correction was offered without preoperative evaluation of pulmonary vascular resistance, because the risk of permanent pulmonary vascular changes was considered to be small within the 1st few months of life. The median age at diagnosis was also significantly lower in recent years. As the use of paediatric echo-

\section{Key messages}

- Attitudes towards evaluating and offering surgery to Down's syndrome patients have changed

- Echocardiography has made it possible to screen all children with Down's syndrome within weeks of birth

- Younger age at diagnosis improves the chances of successful surgery while pulmonary hypertension is still reversible

- Echocardiography has decreased the role of catheterisation as a preoperative investigation method

cardiography became widespread, a shift in the place of diagnosis towards county hospitals was seen. This has made possible echocardiographic examination soon after birth in all children with Down's syndrome. This routine screening reversed the relation in age at diagnosis between children with and without Down's syndrome.

The basic diagnosis of CAVSD by two dimensional echocardiography is considered to be quite straightforward..$^{7-9}$ Our findings of relatively few diagnostic errors using ultrasound were in line with previous reports. ${ }^{3410}$ In our experience, CAVSD was mistakenly diagnosed as a partial defect in one case. The opposite mistake has also been described. ${ }^{4}$ Persistent ductus arteriosus was undiagnosed at the preoperative evaluation in seven cases, this error being confined to both the invasive preoperative study and the two dimensional echocardiography with colour Doppler. An even more important issue is the risk of undiagnosed additional muscular VSDs, because they may necessitate further open heart surgery. Previous reports have shown that their incidence varies from $1-10 \%$ in patients with CAVSD. ${ }^{4} 9^{11} 12$ In several reports, ${ }^{3}{ }^{10} 13$ additional VSDs remained undiagnosed preoperatively when using echocardiography with colour Doppler or invasive evaluation. Therefore, a complementary invasive study has been recommended if an additional VSD is suspected. ${ }^{4}$ In our study, four patients (3\%) had additional muscular VSDs. Others have reported that additional VSDs were more common in children without Down's syndrome. ${ }^{14}$ This was not found to be the case in our study. At present, we routinely add immediate preoperative and postoperative evaluation by transoesophageal echocardiography to detect additional muscular VSDs in these patients.

Extracardiac malformations were seen in $10 \%$ of the children. The most frequently associated malformations were found in the gastrointestinal system. This is not as common with any other cardiac defect, but is consistent with other reports on extracardiac malformations in patients with CAVSD, ${ }^{15}$ and its connection to Down's syndrome is probably stronger than its connection to the heart defect. ${ }^{16}$ Because only life threatening conditions or obvious defects 
were reported in our study, the prevalence of other defects may have been underestimated.

Our finding of Down's syndrome in $85 \%$ of the children is similar to previous reports. ${ }^{17-20}$ There was no sex related difference among children with Down's syndrome and CAVSD but, in children without Down's syndrome, a significantly higher proportion were girls; so far as we know, this has not been reported before. In a recent study, an excess of girls was seen, ${ }^{16}$ but children with incomplete AVSD and other concomitant major heart defects had also been included. In a family pedigree report, AVSD was inherited as an autosomal dominant trait with reduced penetrance, but this was not associated with sex. ${ }^{21}$ In the same study, the region of chromosome 21 associated with the heart defect was excluded as a locus for the malformation. These sex differences and inheritance findings imply that there are various aetiological factors apart from the connection to trisomy 21 involved in atrioventricular septal defects.

In our report, surgery was more frequently denied in the early study period, especially in the presence of Down's syndrome. This is consistent with a report from 1985 in which referral for evaluation and treatment was made later for children with Down's syndrome than for children without. ${ }^{22}$ In another study from 1989 , the time before referral was comparable between Down's syndrome and non-Down's syndrome patient groups. ${ }^{23}$ In a 1995 study, $12 \%$ of all children with Down's syndrome did not live with their biological parents but were waiting for adoption. ${ }^{24}$ In our report, there was a change in parental attitudes and in the general attitude of society regarding the care and treatment of children with Down's syndrome, demonstrated by the total disappearance of institutional care after 1980. Parental refusal of offered surgery was also more common in the early years of our study. The change in attitudes clearly preceded the improved surgical results seen in our institution since the early 1990 s, when the hospital (30 day) mortality rate decreased to only $3 \% .^{25}$ This reflects the development in our country of a general attitude concerning the rights of children with various disabilities having access to equal social and medical treatment.

This work was funded by the Swedish Heart Lung Foundation, the Mayflower Charitable Foundation for Children, and the Swedish Heart-Children's Association.

1 Newfield EA, Sher M, Paul MH, Nikaidoh H. Pulmonary vascular disease in complete atrioventricular canal defect. Am $\mathcal{F}$ Cardiol 1977;39:721-6.

2 Yamaki S, Hisataka Y, Kado $\mathrm{H}$, et al. Pulmonary vascular disease and operative indications in complete atrioventricular canal defect in early infancy. 7 Thorac Cardiovasc Surg 1993;106:398-405.
3 Zellers TM, Zehr RN, Weinstein E, Leonard S, Ring WS, Nikaidoh H. Two-dimensional and Doppler echocardiography alone can adequately define preoperative anatomy and hemodynamic status before repair of complete atrioventricular septal defect in infants $>1$ year old. $7 \mathrm{Am}$ Coll Cardiol 1994;24:1565-70.

4 Marino B, Corno A, Carotti L, et al. Paediatric surgery guided by echocardiography. Established indications and 201.

5 Karlberg P, Taranger J, Engström I. Physical growth from birth to 16 and longitudinal outcome of the study during birth to 16 and longitudinal outcome of the study during
the same age period. Acta Paediatr Scand $1976 ; 258$ (suppl): the $\mathrm{s}$

6 Wood P. The Eisenmenger syndrome or pulmonary hypertension with reversed central shunt. BMF 1958;2: 701-9.

7 Hagler DJ, Tajik AJ, Seward JB, Mair DD, Ritter DG. Realtime wide angle sector echocardiography: atrioventricular canal defects. Circulation 1979;59:140-50

8 Smallhorn JF, Tommasini G, Anderson RH, Macartney FJ. Assessment of atrioventricular septal defects by twodimensional echocardiography. Br Heart $\mathcal{f}$ 1982;47:10921 .

9 Silverman NH, Zuberbuhler JR, Anderson RH. Atrioventricular septal defects: cross-sectional echocardiographic and morphologic comparisons. Int $\mathcal{F}$ Cardiol 1986;13:30931.

10 Santoro G, Marino B, Di Carlo D, Formigari R, Marceletti C, Pasquini L. Patient selection for repair of complete atrioventricular canal guided by echocardiography. Eur $\mathcal{F}$ Cardiothorac Surg 1996;10:439-42.

11 Studer M, Blackstone EH, Kirklin JW, Pacifico AD, Soto B, Chung GKT. Determinants of early and late results of repair of atrioventricular septal defects. F Thorac Cardiovasc Surg 1982;84:523-42.

12 Backer CL, Mavroudis C, Alboliras ET, Zales VR. Repair of complete atrioventricular canal defects: results with the two-patch technique. Ann Thorac Surg 1995;60:530-7.

13 Chin JA, Keane JF, Norwood WI, Castaneda AR. Repair of complete common atrioventricular canal in infancy. $\mathcal{F}$ Thorac Cardiovasc Surg 1982;84:437-45.

14 Carlo D, Marino B. Patient selection for repair of complete atrioventricular canal guided by echocardiography. $\mathcal{f} \mathrm{Am}$ Coll Cardiol 1995;26:574-6.

15 Greenwood RD, Rosenthal A, Parisi L, Fyler DC, Nadas AS. Extracardiac abnormalities in infants with congenital heart disease. Pediatrics 1975;55:485-92.

16 Kallen B, Mastroiacovo P, Robert E. Major congenital malformations in Down syndrome. Am $\mathcal{F}$ Med Genet 1996;65: $160-6$.

17 Alexi-Meskishvili V, Ishino K, Dahnert I, et al. Correction of complete atrioventricular septal defects with the doublepatch technique and cleft closure. Ann Thorac Surg 1996;62:519-25.

18 Bando K, Turrentine MW, Sun K, et al. Surgical management of complete atrioventricular septal defects. A management of complete atrioventricular septal defects. A twenty-year

19 Hanley FL, Fenton KN, Jonas RA, et al. Surgical repair of complete atrioventricular canal in infancy. $\mathcal{F}$ Thorac Cardiovasc Surg 1993;106:387-97.

20 Weintraub RG, Brawn WJ, Venables AW, Mee RB. Two-patch repair of complete atrioventricular septal defect in the first year of life. Results and sequential assessment of atrioventricular valve function. $\mathcal{F}$ Thorac Cardiovasc Surg 1990;99:320-6.

21 Wilson L, Curtis A, Korenberg JR, Schipper RD, Allan L, Chenevix-Trench G. A large, dominant pedigree of atrioventricular septal defect (AVSD): exclusion from the Down syndrome critical region on chromosome 21. Am f Hum Genet 1993;53:1262-8

22 Sondheimer HM, Craig JB, Blackman MS. Unequal cardiac care for children with Down's syndrome. Am $\mathcal{F}$ Dis Child 1985;139:68-70.

23 Schneider DS, Zahka KG, Clark EB, Neill CA. Patterns of cardiac care in infants with Down's syndrome. Am F Dis Child 1989;143:363-5.

24 Reynier CJ, Aurran Y, Dumaret A, et al. Attitudes towards Down syndrome: follow-up of a cohort of 280 cases. $7 \mathrm{Med}$ Genet 1995;32:597-9.

25 Åmark K, Sunnegårdh J, Berggren H, Südow G. Diagnosis and surgery in complete atrioventricular septal defect: a 20-year experience. In: Imai Y, Momma K, eds. Proceedings of the Second World Congress of Pediatric Cardiology and Cardiac Surgery 1997. New York: Futura Publishing Company, 1998:905-7. 